\title{
Mission-Oriented Missile Equipment Support System Modeling: Considering the Failure and Health State
}

\author{
Lu Guo $\mathbb{D}^{1,2}$ and Xiaodong Liu ${ }^{1}$ \\ ${ }^{1}$ School of Equipment Management and UAV Engineering, Air Force Engineering University, Xi'an, 710051, China \\ ${ }^{2}$ Jiangnan Mechanical and Electrical Design Institute, Guiyang 550009, China \\ Correspondence should be addressed to Lu Guo; 13259463270@163.com
}

Received 17 November 2021; Revised 7 January 2022; Accepted 10 January 2022; Published 31 January 2022

Academic Editor: Guozeng Cui

Copyright (c) $2022 \mathrm{Lu}$ Guo and Xiaodong Liu. This is an open access article distributed under the Creative Commons Attribution License, which permits unrestricted use, distribution, and reproduction in any medium, provided the original work is properly cited.

\begin{abstract}
Missile equipment support system is a complex system involving mission profile, operating environment, support personnel, resource scheduling, and other factors, and most of the equipment failures are a process of continuous evolution over time. Based on the characteristics of equipment functions or performance parameters and current detection methods, only part of equipment health degradation trend can be monitored. Therefore, it is necessary to carry out the support system simulation considering the equipment failure and health state comprehensively. In this paper, a mission-oriented modeling framework of missile equipment support system based on agent is proposed. Agents of equipment, support, management, and environment are abstracted. The behavior logic, information transmission link, and interaction mechanism among agents are explained. The failure occurrence handling mechanism and health state degradation handling mechanism are determined. The equipment recovery behavior model, including equipment health state control model, corrective maintenance behavior model, and system reconstruction behavior model, are constructed, and the simulation process and implementation method are explained. Finally, a certain type of missile equipment is taken as an example for simulation. The results show that the mean time between failures can be extended and the times of corrective maintenance can be reduced by maintenance support with integrated consideration of equipment failure and health deterioration. In addition, the simulation results show the variation trend of equipment availability, which can lay a solid foundation for the optimization design of equipment support resources in the future, so as to improve the availability of equipment in the whole life cycle.
\end{abstract}

\section{Introduction}

As a typical complex system, the support system of missile equipment involves multiple complex elements such as mission profile, support personnel, operating environment, and resource scheduling, and is characterized by complex functional composition, complex operating process, and complex resource types and constraints [1]. As the complexity of missile equipment support system increases, it becomes more difficult to define its required constraints and variables and to describe its support process through deterministic methods [2]. However, the emergence of simulation technology can deal with these complexity problems [3]. For a long time, many developed countries have been paying close attention to the development of simulation technology, and have been committed to the practical application of simulation technology. In particular, the U. S. Department of Defense regards simulation and modeling technology as an important factor in national defense technology [4]. When considering the influence of maintenance decision and support resources on the combat readiness of missile equipment, the simulation model is the most economical and effective method [5].

In recent years, equipment support researchers have adopted a variety of modeling methods to describe the maintenance support process of equipment $[6,7]$, such as Petri net model [8-10] adopted by many scholars, expert knowledge system model [11], proportional hazards model [12], wiener process model [13], stochastic model [14], deep learning model [15], neural networks model [16], and fuzzy logic model [17]. 
At first, the support simulation technology is based on discrete event simulation. In the modeling method, simulation algorithm, and system design, the requirements of parallel computing and distributed computing are not taken into account, resulting in low efficiency of system operation. With the gradual popularization of concurrent engineering and the gradual implementation of distributed collaborative modeling and simulation environment, simulation environment has been transformed into a new integrated environment with integration as the core and distributed and collaborative mode as the performance. The traditional support simulation system does not support the distributed cooperative environment. Modeling and analysis need to be done centrally. Not only the workload is large and the cycle is long but also the analysis data and model of each subsystem cannot be used effectively, which makes it difficult to adapt to the development of missile equipment support system. For example, the high-level architecture (HLA) model implemented by the U. S. Department of Defense is the supporting technology of complex system modeling and simulation. HLA-based support simulation enables the simulators to focus on the development and design of the simulation model without caring about how to complete the communication of data information. However, the basic components of HLA can only appear in the way of a member, who does not have intelligence, and the simulation granularity is not detailed enough. As the requirements for granularity and intelligence of missile equipment support simulation continue to improve, these methods can no longer fully meet the comprehensive needs of equipment support. Agent-based technology has gradually become a new trend of equipment support modeling and simulation $[18,19]$.

The agent simulation modeling technology is developed from distributed artificial intelligence technology, which solves the modeling and simulation of complex systems by studying the interaction, coordination, and cooperation among multiple agents [20]. Especially for the modeling and simulation of a large complex system, it can not only improve the interaction and intelligence of simulation object and model but also reduce the coupling of the system [21]. In this method, an individual is a single agent with sensibility, cooperation, and interaction. Different agents interact with each other and are subject to various influences from the environment, which can show simulation effects consistent with real individual characteristics [22]. Study in Ref. [23] proposed decomposition modeling of integrated battlefield environment simulation system based on multi-agents, and then used distributed simulation technology to realize the simulation system. The results show that agent technology can not only reduce the complexity of simulation system model but also make simulation members have certain intelligence.

The modeling and simulation method of support system based on agent can be flexibly designed in different ways according to specific requirements. Agents can be abstracted at different levels to ensure proper simulation granularity. The agent-based simulation method has two main drawbacks: First, the communication within and between agents must be artificially designed by the knowledge query and manipulation language (KQML). Second, as the granularity becomes smaller, the amount of computation will increase significantly. But with the development of parallel computing and cloud computing technology, this problem can be solved well. The application of agent technology in missile equipment maintenance and support system has good adaptability.

At present, most scholars build models based on traditional maintenance support schemes, and then simulate and optimize them, so as to propose more reasonable maintenance support decisions. For missile equipment, due to the fact that outside world and its own situation are complicated and changeable in the process of executing the mission [25], and the equipment is usually in humid, mildew, salt fog, or high altitude environment, the equipment system or its components are due to fail [26], or change with the passage of time, space, and environment, with the appearance of fracture, wear and tear, corrosion, aging. As a result, the equipment loses its original performance or function, and the work efficiency is reduced and the mission is interrupted [27]. Moreover, the degradation degree of equipment components varies greatly, which makes it more difficult to allocate the originally limited maintenance resources and support personnel reasonably [28].

In the actual maintenance process, for missile equipment with multiple components, several health degradation events often occur simultaneously or successively in a certain period of time. Failure rate of equipment cannot be reduced by health control decision if only failure-based maintenance is considered and health-based maintenance is not considered. This will not only lead to the waste of maintenance manpower and support resources but also may lead to the loss of downtime costs and reduce the effective use of equipment. Since the health state of different components has different impacts on the mission execution of equipment, it is necessary to make comprehensive decisions on the health state degradation events of components based on the mission. Early or delayed maintenance can be adopted to improve maintenance efficiency and reduce maintenance costs while reducing maintenance downtime.

In most cases, the failure of missile equipment is a process of continuous evolution over time, so it is necessary to carry out maintenance support simulation considering the changes of missile equipment health state [29]. During the operation of the missile equipment, it is impossible to observe the health state of the equipment [30]. The specific performance index of the equipment should be monitored and the corresponding index range should be established to determine its health level [31, 32]. According to the health level of the equipment, the corresponding control measures are taken to improve the health level of the equipment and reduce the probability of failure [33].

Due to the limitation of the actual situation of the missile equipment, it is impossible to install sensors on all kinds of equipment. This causes the data passed to the simulation model to be roughly divided into two categories: health state 
data and normal failure data. If the actual operating parameter data of the equipment can be read, the current health state of the equipment is evaluated and then transmitted to the simulation model for generating maintenance support task planning. If there is no sensor installed in the equipment, the actual operation data will not be transferred effectively and in real time to the support simulation model. Only when the equipment fails, the simulation model can accept its state changes and provide data for subsequent maintenance support task planning.

Based on the analysis of the support process and evaluation indicators in typical mission scenarios of missile equipment, this paper takes the agent technology as the basis and makes use of the support data of missile equipment to establish agents of equipment, support, management, and environment. The simulation framework of the missile equipment support system based on agent is established, and two cases consisting of equipment failure and health degradation are considered. The failure and health degradation processing mechanism are established. Health state control model, corrective maintenance model, and system reconstruction model are established, and the equipment support system simulation is carried out. In this method, various attributes of missile equipment are considered comprehensively, and accurate support model is established according to the actual situation of the missile equipment. Reasonable health control strategy is proposed according to the health state of the missile equipment, in order to slow down the degradation of the equipment health state and improve equipment availability and reduce equipment maintenance and support work.

\section{Overall Simulation Architecture}

In the operation of the missile equipment, the system will appear to have many kinds of disturbances which can affect the execution of the mission. Among them, equipment health degradation and failure occurrence are the disturbances most often found in the system. Health state and failure of the equipment are closely related to its own structure, failure rate, and operating environment. The simulation system based on an agent can simulate the degradation of health state and occurrence of failure and the corresponding recovery behavior. For the agent model, health state degradation and failure behavior are equivalent to the change of health state parameters of the equipment agent or support agent corresponding to the function unit. Health state degradation and failures in the simulation system are transmitted to the target agent as signals, and the agent receiving the signals changes its own corresponding parameter values and updates the parameter data of the system, and provides feeds back to the management agent at the same time. The management agent coordinates the support agent to maintain the equipment agent according to the equipment task plan and support resources, and makes new plans for the operation of the equipment support system. In the modeling of health state degradation and failure, the stochastic failure of the equipment agent caused by its own failure is mainly considered. According to the failure rate and reliability function of all units in the equipment agent that will lead to health state degradation or failure of equipment, the failure time is randomly selected, and the health degradation and failure time are monitored by a simulation clock. When the simulation clock goes to zero, the health state degrades or fails. In the normal simulation process, the equipment agent detects the clock zero signal, and automatically changes the relevant parameters of the current agent to the health state degradation or failure state. The management agent determines whether to terminate the current activity and join the waiting queue for maintenance, or switch to another running logic.

Missile equipment maintenance and support is a kind of complicated decision-making problem, and it is very difficult to study this kind of problem considering all the small aspects, which is not consistent with the purpose of engineering practice. Therefore, it is necessary to clarify the emphases of simulation and put forward reasonable assumptions. The necessary assumptions of this paper are as follows:

(1) The state of the equipment maintained based on health state can be monitored in real time.

(2) When the equipment is in operation, its remaining life will be reduced. When the equipment is on standby, its remaining life does not change.

(3) The reliability model of a single equipment is treated as a series model. Monitoring components on an equipment are usually critical components. Therefore, when critical components fail, the equipment will also fail.

(4) The maintenance method adopted for each faulty equipment is replacement repair, so the state of the repaired equipment can be regarded as the new state. During replacement, the failure rate of the equipment (spare parts) is 0.

(5) If the equipment is still in the maintenance state at the beginning of the mission, the equipment cannot execute the mission.

(6) Considering the constraints of maintenance capability of a support point, a support point can only maintain one equipment at a certain time.

(7) The maintenance time and cost of the same type of components are the same.

(8) When there is an opportunity for maintenance, multiple components in the equipment can be repaired simultaneously. In this case, the maintenance time of a single equipment is the longest among all the maintenance, while the maintenance cost is the total maintenance cost of all the maintenance.

2.1. Modeling Framework. An agent is an entity that can function in a distributed or collaborative system. Through agent-oriented analysis of the system, various agents and their attributes can be abstracted, and the multi-agent 
system (MAS) architecture can be established through the relationship between agents.

Firstly, the missile equipment agent is abstracted, and the attributes of various agents are analyzed, including space-time attributes and characteristic attributes. Secondly, the state and behavior of various agents are sorted out, such as idle state, standby state, working state, health state, failure state, test state, and maintenance state. Thirdly, the interaction between agents is clarified, including the normal function behavior, failure behavior, health degradation behavior, health control behavior, and maintenance behavior of agents. Finally, the life state diagram of each type of agent is determined, and the environment awareness and message module, behavior planning model, action execution module, and internal state library are emphatically considered, and the simulation model of missile equipment support system is established. Missile equipment support system construction framework is shown in Figure 1.

2.2. Modeling Process. The agent-based modeling process is divided into two main stages: analysis stage and design stage. Each stage consists of a specific set of steps. The analysis stage consists of five steps: problem and target definition, role-based task decomposition, agent function and failure/ health state description, agent identification and MAS architecture definition, and system environment conditions determination. At the same time, there is an iterative relationship between the first four steps in order to obtain satisfactory analysis results. In the design stage, there are four steps: establishing agent cooperation mechanism, defining agent internal logic, defining environment agent, realizing agent and assembling MAS. The missile equipment support system model can be established by carrying out corresponding modeling activities according to these steps. The modeling process of missile equipment support system is shown in Figure 2.

The main task of the analysis stage is to determine the failure-/health-state-related behaviors of missile equipment in the process of completing the mission, and the environmental conditions that must be considered in the modeling, and to define the types and quantities of agents, their roles, and main behaviors, starting with the key factors that affect mission success. The final output of this phase is the MAS architecture, agent properties and functions, fault/ health state behavior, and environmental condition analysis list.

The main task of the design stage is to design various behaviors of the agent in the mission according to various behaviors of the missile equipment support system, and establish the coordination mechanism among agents and the reasoning logic within agents. The other task is to complete the construction of the environment agent, with which other agents interact to obtain the environment information.

2.3. Agent abstract Type. Based on the above analysis, missile equipment is abstracted into four types of agents: equipment agent, support agent, management agent, and environment

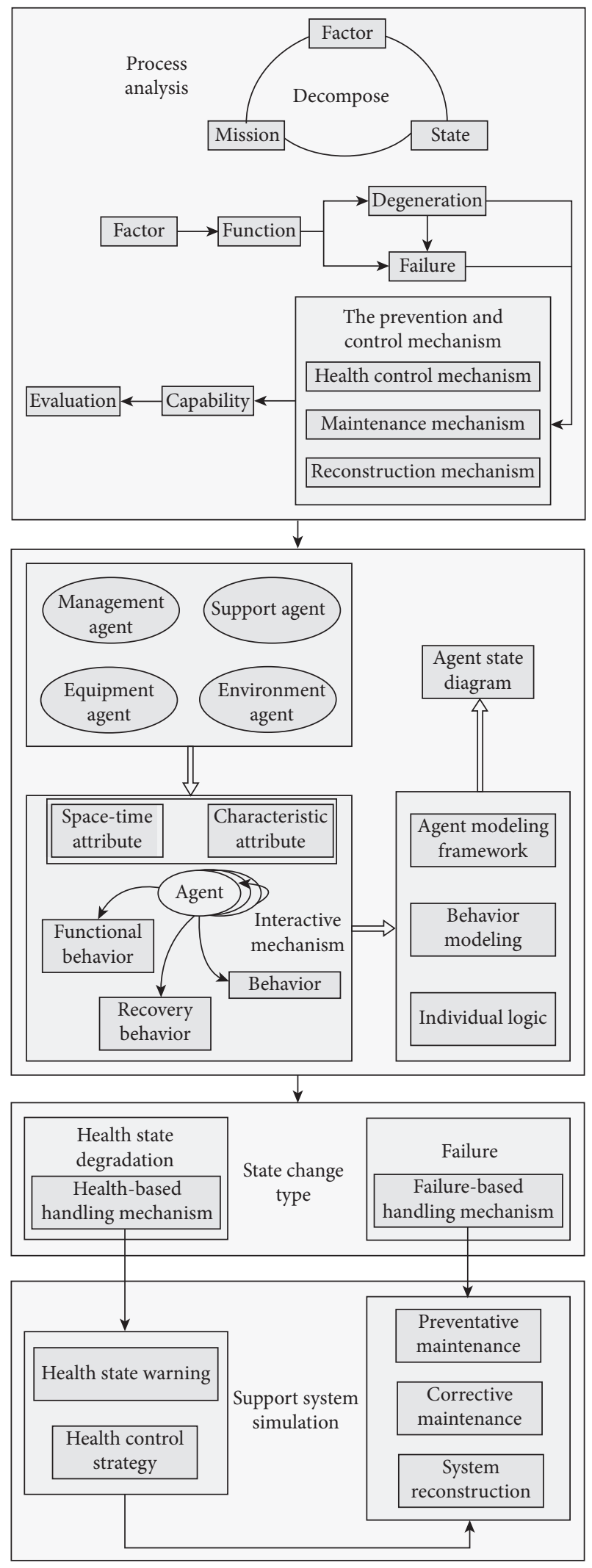

FIGURE 1: Equipment support system construction framework.

agent. Among them, the equipment agent and support agent come from the components of the missile equipment and support system. 


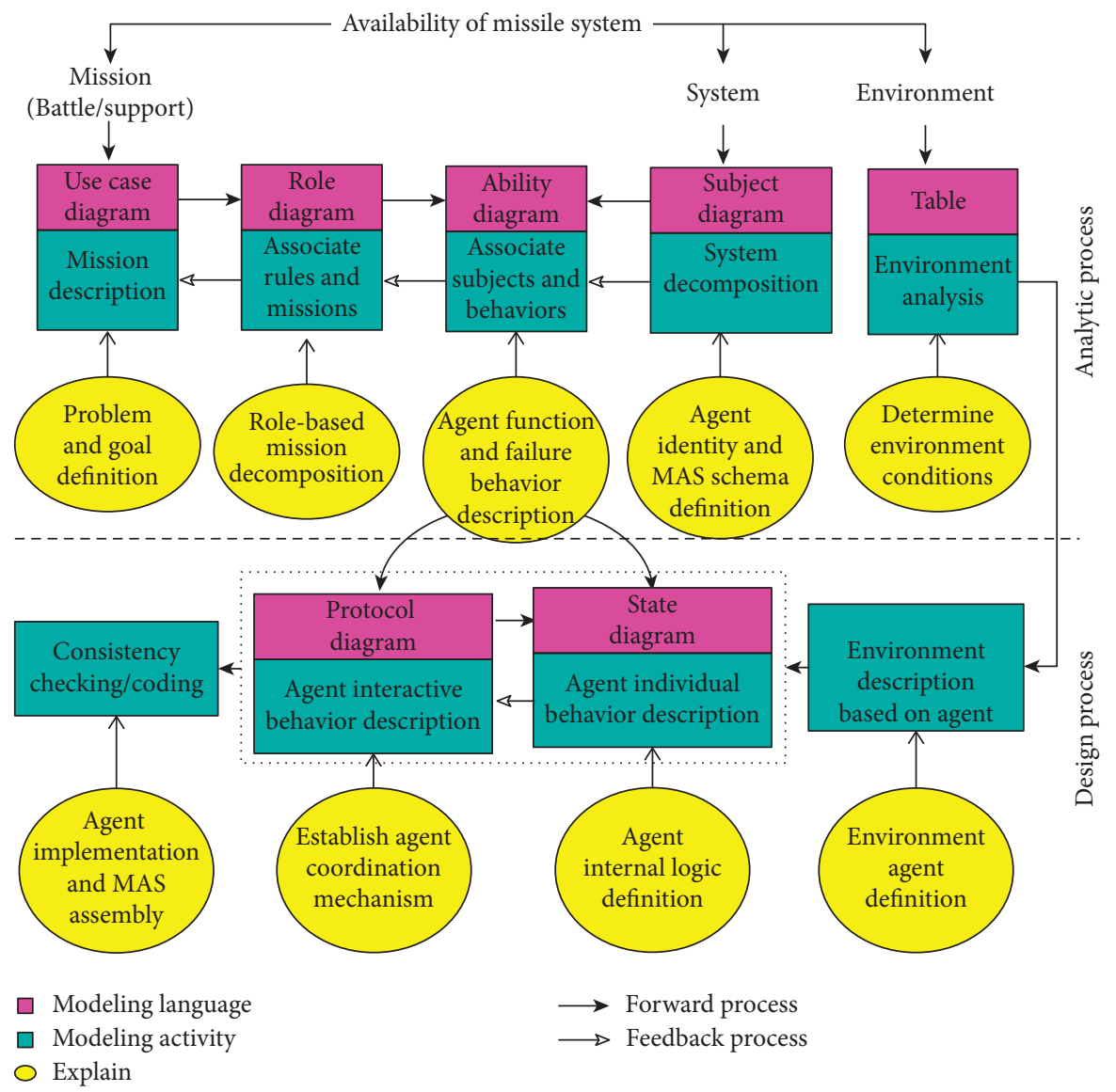

FIGURE 2: Modeling process of missile equipment support system.

Equipment agent is the abstraction of command and control vehicle, antenna receiving and transmitting vehicle, missile launching vehicle, power distribution vehicle, transportation and loading vehicle, and other equipment. Various types of parameters, including description parameters, space-time parameters, physical parameters, and ability parameters, are used to describe equipment agent attributes. Typical parameters of the equipment agent are shown in Table 1.

Support agent is the abstraction of support personnel, support equipment, support facilities, and support materials involved in the process of equipment storage, use, and maintenance. In other words, support agent is a complex that has certain resources and can provide services or materials independently. Description parameters, spacetime parameters, support resource parameters, and support capability parameters are used to describe the support agent attributes.

Management agent comes from the command and management process in the operation of the equipment support system. Management agent is the abstraction of the command and management process of the missile equipment, which is usually task-driven and does not contain specific attributes. In the security system, the management agent mainly has the functions of collecting and processing global operation data and conveying control information.
According to the difference between functions, the management agent can be divided into state monitoring agent, computing decision agent, and management control agent.

Missile equipment will face different environments during operation, so the environment agent needs to be set. An environment agent is the abstraction of natural environment, induced environment, mechanical environment, and attack target. Time and state parameters are used to describe the attributes of the environment agent. The environment agent can affect the abilities of other agents.

Since the real equipment and support system must play a role under command and management, the corresponding equipment and support agent has a strong semi-autonomous feature. That is, in the interaction, the management agent has a higher priority than the equipment agent and support agent.

2.4. Agent Interaction Mechanism. After the establishment of the agents of equipment, support, management and environment, behavioral logic, and information transmission links between agents should be determined. The link diagram of the missile equipment support process is shown in Figure 3.

Based on the link diagram of the missile equipment support process, a multi-agent hybrid control structure is 
TABLE 1: Typical parameters of the equipment agent.

\begin{tabular}{|c|c|c|}
\hline Parameter types & Parameter names & Functions \\
\hline Description parameters & $\begin{array}{l}\text { Number } \\
\text { Support type } \\
\text { State type } \\
\text { Sequence }\end{array}$ & $\begin{array}{l}\text { Describe the number of the equipment agent } \\
\text { Describe the support type of the equipment agent } \\
\text { Describe the state of the equipment agent } \\
\text { Describe the marching sequence of the equipment agent }\end{array}$ \\
\hline Space-time parameters & $\begin{array}{l}\text { Point } \\
\text { Time } \\
\end{array}$ & $\begin{array}{l}\text { Describe the location of the equipment agent } \\
\text { Describe the time of the equipment agent in a process or state }\end{array}$ \\
\hline Physical parameters & $\begin{array}{l}\text { Length } \\
\text { Width }\end{array}$ & $\begin{array}{l}\text { Describe the length of the equipment agent } \\
\text { Describe the width of the equipment agent }\end{array}$ \\
\hline Ability parameters & $\begin{array}{l}\text { MTBF } \\
\text { MTTR }\end{array}$ & $\begin{array}{l}\text { Describe the mean time between failures of the equipment agent } \\
\text { Describe the mean time to repair the equipment agent }\end{array}$ \\
\hline
\end{tabular}

designed and a global-local multi-layer scheduling mode is established, as shown in Figure 4.

Among them, the management agent is at the highest level and manages the interaction process of agents to ensure the smooth progress of interaction. The support agent collaborates with the equipment agent to complete the support work. The environment agent creates disturbance to each agent interaction. The management agent is responsible for global scheduling. When the management agent receives the failure or health state notification sent by the equipment agent, it carries out the overall coordination and control to generate the overall maintenance strategy and optimize the global configuration of support resources. Local scheduling occurs between equipment agent and support agent, and focuses on the realization of specific maintenance operations. The support mechanism of the missile equipment involves the interaction between the above agents, and the interaction relationship mainly includes the following three types: competition, cooperation, and coordination.

\section{State Change Handling Mechanism}

Some parameters reflecting the missile equipment state can be measured and some cannot be measured. It is necessary to consider the function, structure, and failure characteristics of the equipment comprehensively, and gradually select and determine the parameters that can indicate the health state of the equipment and the parameters that cannot. Based on these two kinds of parameters, the data passed to the simulation model will be divided into two types: health data and normal failure data.

If the parameters of the equipment cannot indicate its health state, the equipment is set as failure-based maintenance equipment. This type of equipment is abstracted into a "two-state" unit, that is, a "normal" state and a "failure" state. If the equipment is faulty, the state changes from normal to failure. After the faulty equipment is repaired, its state changes from failure to normal.

If the parameters of the equipment can indicate its health state, the equipment is set as health-based maintenance equipment. When the health state of the equipment degenerates, the simulation model can receive the change data of its state. The state of the equipment is classified into healthy, sub-healthy, dangerous, and abnormal state.
3.1. Failure Occurrence Handling Mechanism. The failure behavior of the equipment is caused by the failure of one or part of the work unit. For the agent model established, the failure behavior is equivalent to the change of the parameters of equipment agent or support agent to which the failure unit belongs. During the operation of the system, failure is transmitted to the target agent (equipment agent) as a "signal". The agent receiving the failure signal changes its own corresponding parameter value, and updates the parameter data of the system, and feeds back to the management agent. Under the guidance of the management agent, a new round of planning is carried out for the operation of the system, including arranging the maintenance of the equipment agent by the support agent and updating the task planning of the equipment agent (system reconstruction). The failure occurrence handling mechanism of the missile equipment is shown in Figure 5.

3.2. Health State Degradation Handling Mechanism. With the change of time, the health state of the missile equipment degrades continuously, which is manifested by the decrease of various performances and functions. At the same time, it will lead to abnormal symptoms, behavior, characteristics, and ability. In particular, the ability to perform mission and the ability to adapt to the environment is weakened or even lost.

As shown in Figure 6, $\mathrm{A}$ is the beginning point of health degradation. $\mathrm{P}$ is the potential symptom point that can be detected. I is the occurrence point of failure. $T$ is the time interval between the potential symptom point and the failure occurrence point. Potential symptoms here can be identified by observation or testing; otherwise, it is considered that there are no potential symptoms. According to the health degradation curve, the health state of the equipment is divided into healthy, sub-healthy, dangerous, and abnormal state, and the corresponding health levels are the blue level, yellow level, orange level, and red level, which are represented by $4,3,2$, and 1, respectively. According to the degradation rule of the equipment maintained based on health state, the parameter value interval of different levels is set.

The equipment agent receives the task instruction issued by the management agent and is in the task state. At this point, the 


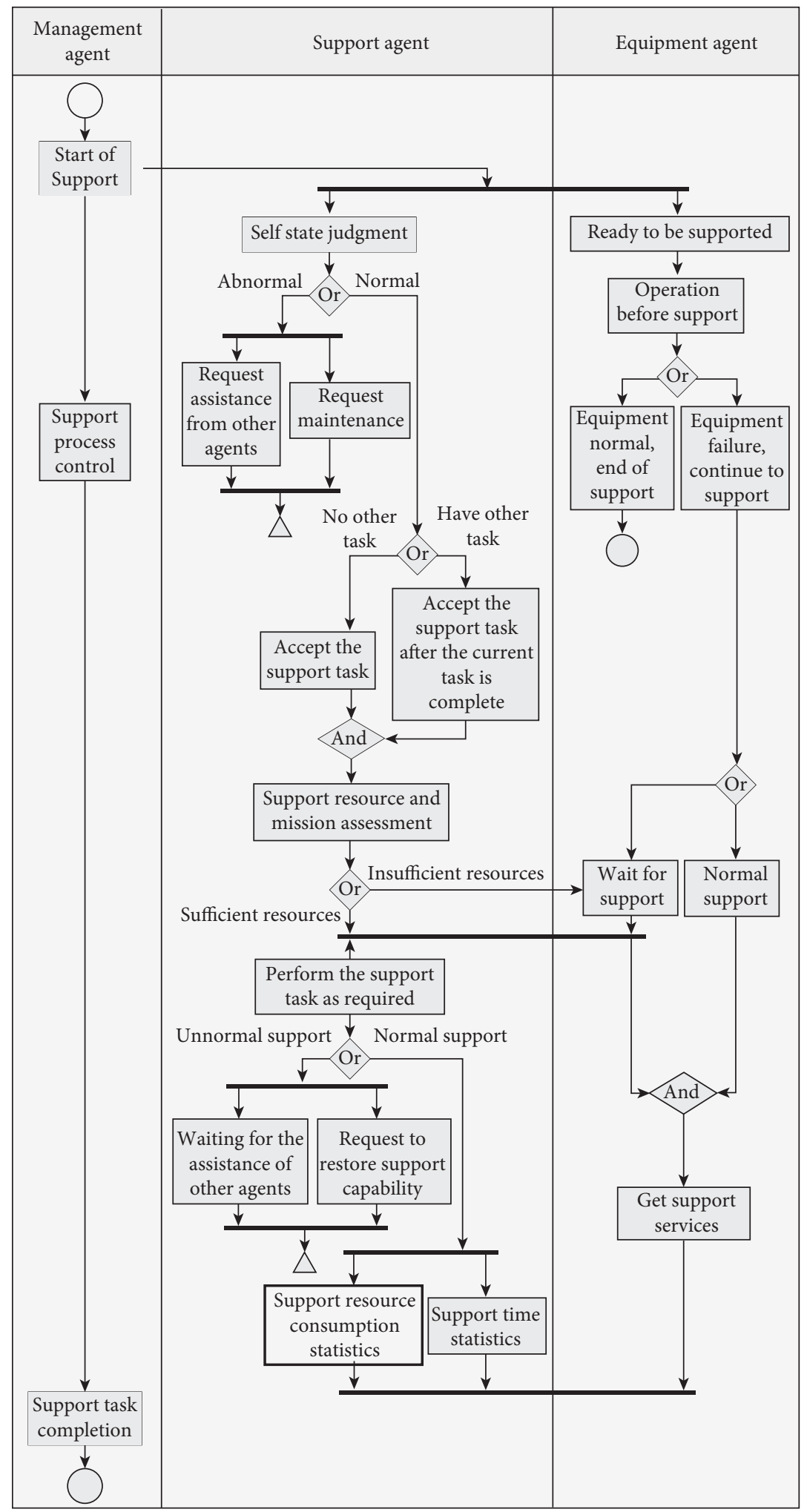

FIGURE 3: Link diagram of equipment support process.

health state simulation process begins. If the health level of the agent is lower than the yellow level, the agent sends a warning signal to the management agent. The management agent receives the warning information of the equipment agent, and determines whether to allow it to exit the system, and whether to arrange other equipment agents in standby state to join the system to continue to execute tasks. The health state degradation handling mechanism is shown in Figure 7. 


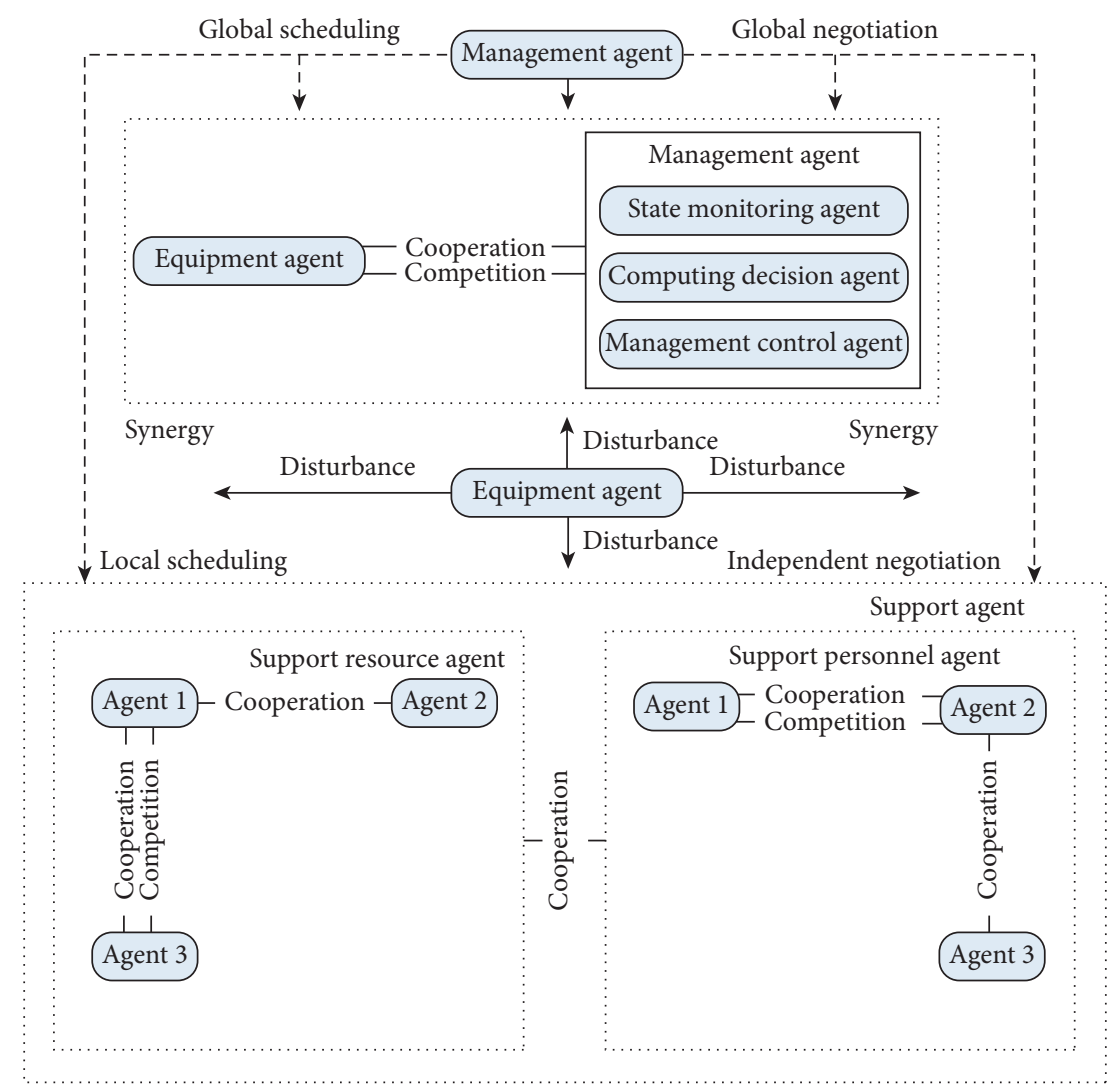

FIGURE 4: Interaction framework between agents.

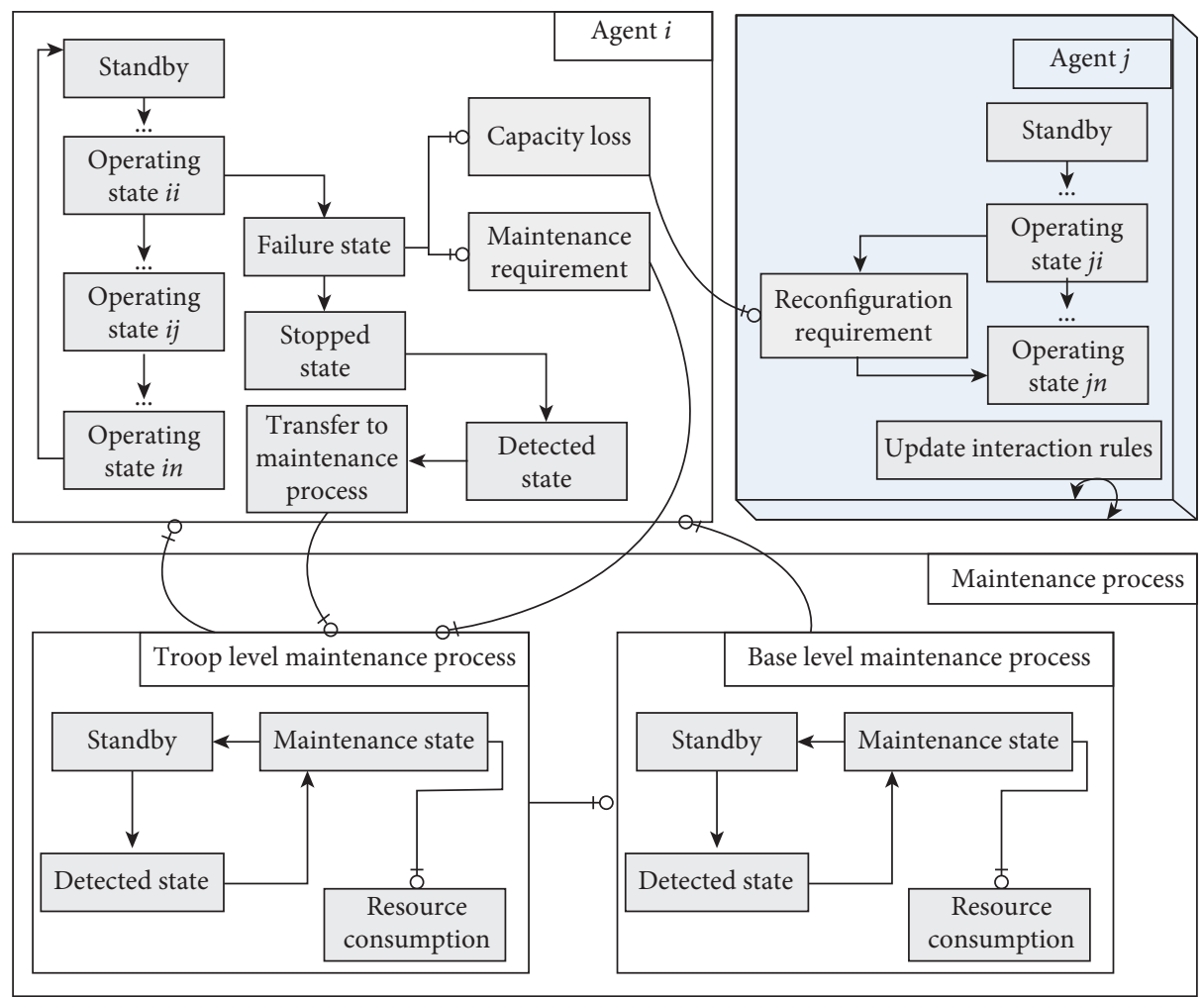

Figure 5: Failure occurrence handling mechanism. 


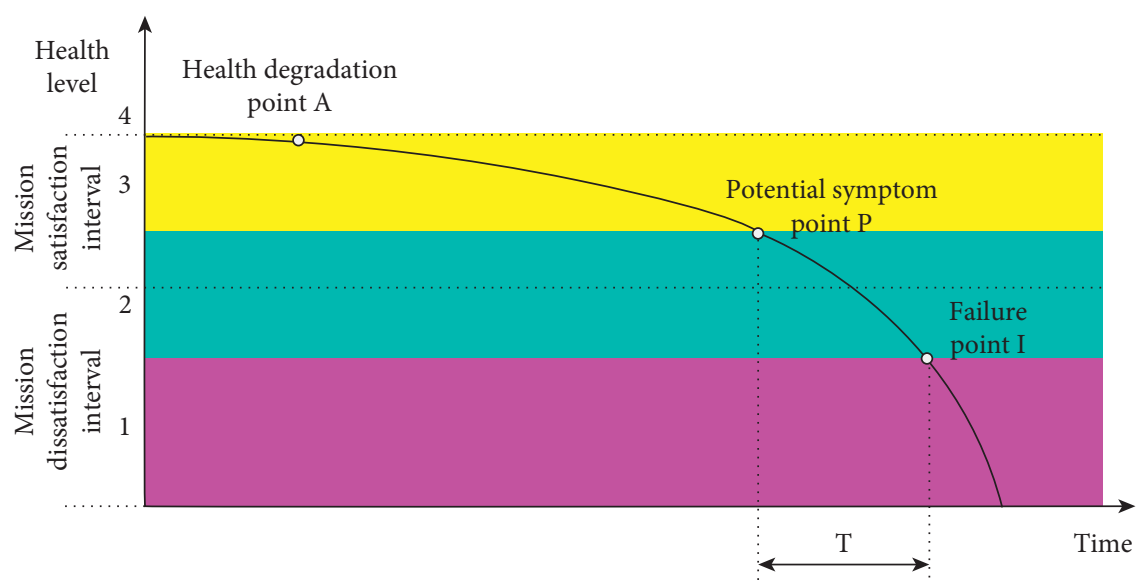

Figure 6: Health state degradation process.

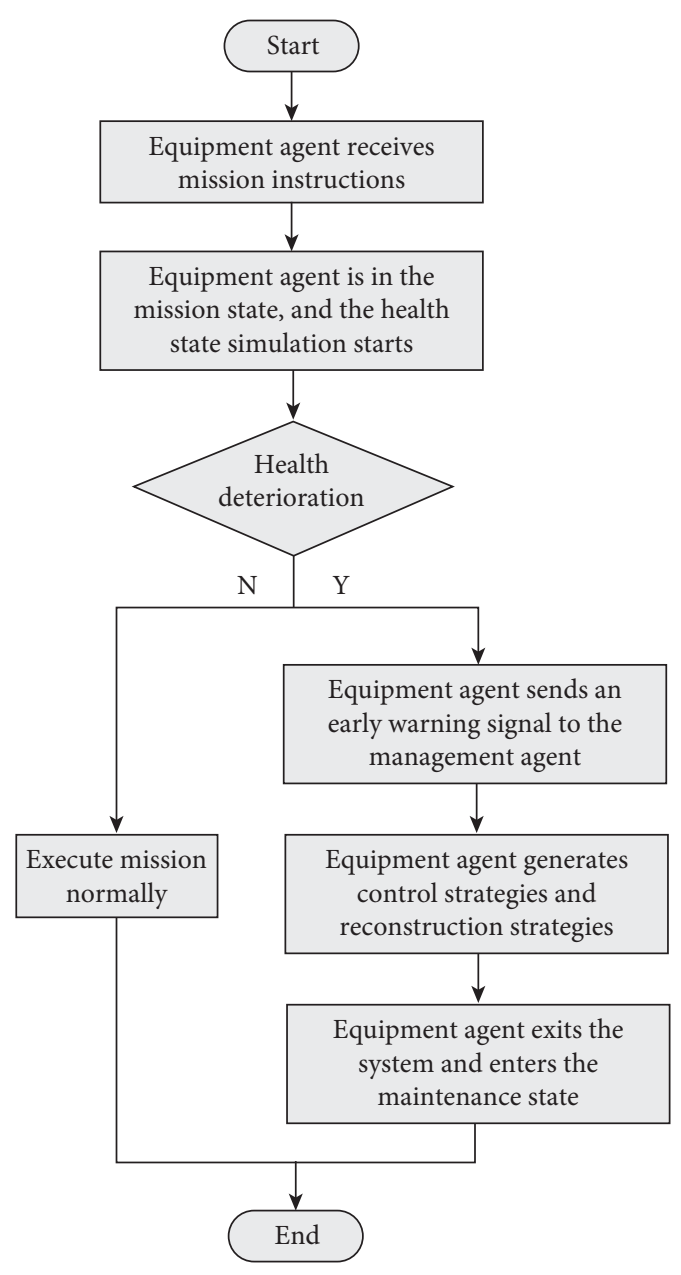

Figure 7: Health state degradation handling mechanism.

\section{Recovery Behavior Modeling}

4.1. Health State Control Modeling. Equipment changes from health to sub-health to danger to abnormality state, which is a dynamic process of quantitative change to qualitative change. The sub-health state refers to the state in which the equipment has not yet failed, but degrades in function and performance. The sub-health state is characterized by bidirectional transformation. Only by accurately judging the current health state of the equipment and diagnosing and handling the problem in time before the abnormal state occurs can failures be avoided. If the health control strategy is made properly, the health level can be improved, and subhealth can be transformed into health. If the health control strategy is improper or not diagnosed or treated, the health level will continue to decline, and sub-health will develop into abnormality or even complete failure. Therefore, it can be said that the core of health management is to control "variation", maintain "health", and try to block the natural process of "disease."

Therefore, it is necessary to establish equipment health state control model. Health state control mainly includes two parts: early warning and control strategy. According to the current performance parameter value of the equipment and the set early warning condition, judge whether early warning is needed, and formulate reasonable health control strategy. The steps of the missile equipment health state control modeling are as follows:

Step 1: classify the missile equipment health level. According to the degradation characteristics of equipment performance, the health level of the equipment is divided into four levels: blue level, yellow level, orange level, and red level, which are represented by $4,3,2$, and 1 , respectively.

Step 2: forecast missile equipment health state. According to the performance degradation amount of the equipment, set the threshold value of the equipment at blue level and red level as $H_{1}$ and $H_{4}$, respectively. If $H_{1}<H_{4}$, the range of performance parameter values of the equipment at blue level, yellow level, orange level, and red level are $\left(-\infty, H_{1}\right],\left(H_{1}, H_{2-3}\right),\left[H_{2-3}, H_{4}\right)$, and $\left[H_{4},+\infty\right)$, respectively. If $H_{1}>H_{4}$, the range of performance parameter values of the equipment at blue level, yellow level, orange level, and red level are $\left(+\infty, H_{1}\right], \quad\left(H_{1}, H_{2-3}\right), \quad\left[H_{2-3}, H_{4}\right)$, and $\left[H_{4},-\infty\right)$, respectively. Determine the health level of the equipment based on the range of performance parameters and provide corresponding prompts. 
Step 3: formulate health control strategies. According to the equipment characteristics and the defined health level, the corresponding maintenance support decision is put forward. Different health control strategies should be adopted for different health levels of the equipment. The health control strategies for each health level are shown in Table 2.

The simulation process of the health state of the equipment agent is accompanied by the whole mission process. The equipment agent transmits data according to the simulation step. Management agents include state monitoring agent, computing decision agent, and management control agent. The computing decision agent receives health state data of the equipment agent, and determines the health level of the equipment agent based on the range of performance parameters, and sends the health level to the state monitoring agent. The state monitoring agent sends an early warning and transmits the simulation data of the equipment agent to the computing decision agent. The computing decision agent invokes the corresponding control strategy. If the equipment is in a ready state and there is no task plan between the required maintenance periods, the maintenance is carried out directly. If there is a task plan, determine whether maintenance can be completed before the task plan starts. If yes, continue to arrange the equipment task; otherwise, abort the equipment task and transfer it to some other equipment for execution. The computing decision agent will feed back the control strategy to the management control agent, and the management control agent will aid the support agent to complete the maintenance work. The logic of the missile equipment health state control is shown in Figure 8.

4.2. Corrective Maintenance Behavior Modeling. One of the important recovery behaviors of missile equipment is corrective maintenance. Corrective behavior may be triggered by either post-failure or state degradation. For the whole missile system, because the maintenance support resources are limited, it cannot meet the condition wherein the corresponding maintenance activities can be provided when a certain equipment needs maintenance. Therefore, the task requirements, equipment state, and available support resources should be taken into consideration when formulating the maintenance strategy, and maintenance resources should be allocated uniformly.

According to the analysis of missile equipment maintenance elements, the equipment corrective maintenance model architecture is presented in Figure 9. The basic idea is to first associate the agent with the role and confirm the goal it needs to accomplish or the function it needs to undertake. Then, the task is decomposed in detail by referring to the condition in which the entity corresponding to the agent achieves the goal or function. Finally, the behavior sequence of the agent under a certain goal or function is determined through iteration.

4.3. System Reconstruction Behavior Modeling. When the equipment agent exits the system due to failure or health degradation that cannot meet task requirements, the management agent generates maintenance strategy and arranges a support agent to repair equipment agent. At the same time, in order to meet the task requirements, the equipment agent will generate a reconstruction strategy according to the real-time situation, and arrange the standby equipment agent to rejoin the task sequence.

Figure 10 shows the reconstruction method based on contract network. $C_{f}$ represents the equipment agent that cannot continue to undertake system tasks or functions and causes system reconstruction. $C_{o}$ represents the task management agent in the reconstruction process and coordinates the reconstruction process. $C_{a}$ is the reconstruction responder, representing the equipment agent participating in the reconstruction, to compensate for the function loss caused by the exit of $C_{f}$ from the system. The main steps are as follows:

Step1: $C_{f}$ sends a request to the $C_{o}$ to exit the system and sends a message about system reconstruction.

Step2: $C_{o}$ confirms and allows $C_{f}$ to exit the system, and performs reconstruction and collaborative management.

Step3: $C_{o}$ carries out reconstruction bidding according to system performance loss, and issues reconstruction objectives and requirements.

Step4: $C_{a}$ bids according to its own judgment and submits its ability to participate in reconstruction.

Step5: $C_{o}$ judges whether $C_{a}$ meets the reconstruction requirements according to the corresponding situation. If the reconstruction requirements are met, the contract authorization will be carried out; if not, the coordination will be abandoned.

Step6: after $C_{a}$ is authorized, it confirms authorization to $C_{o}$ and undertakes the system reconstruction task.

Step7: After receiving the confirmation information, $C_{o}$ assigns specific reconstruction tasks to $C_{a}$.

Step8: $C_{a}$ accepts the assigned reconstruction task and requests cooperation with other agents.

Step9: $C_{o}$ receives the coordination request and begins to coordinate $C_{a}$ and other agents.

Step10: Under $C_{o}$ coordination and management, $C_{a}$ provides reconstruction service and enters the reconstruction state.

Step11: After the reconstruction, the system output becomes stable again. The reconstruction task is terminated and the reconstruction process is complete. $C_{o}$ switches from the reconstruction state to the working state.

\section{Instance Analysis}

The following takes a certain type of air defense missile weapon system as an example to conduct simulation experiments. Firstly, the equipment structure tree analysis and failure mode and effects analysis (FMEA) are carried out to determine the health-based maintenance unit and the 
TABLE 2: Health levels and control strategies.

$\begin{array}{lll}\begin{array}{l}\text { Health } \\ \text { levels }\end{array} & \text { Equipment states } & \text { Health control strategies }\end{array}$

levels

The state that has no impact on the performance.

Blue level

Performance parameters are within the normal range. The equipment is fully functional and there is a long time before

No support measures are taken. the failure.

Yellow The state that has little impact on the equipment executing it mission. Performance parameters have a tendency of level degradation, but there is still a long time before the failure.

A signal can be transmitted to indicate that the equipment needs maintenance. Some auxiliary measures can be taken to reduce the rate of equipment degradation, such as ventilation and cleaning, to improve equipment work or storage environment.

The state that greatly affects the performance. Performance Orange parameters are close to the failure thresholds. Although level failure has not occurred, but it can obviously show a trend of degradation. The probability of failure is greatly increased.

The state that has a significant impact on the equipment executing its mission. Performance parameters have reached the failure thresholds. The equipment has failed and cannot work properly.

A signal can be transmitted to indicate that the equipment needs maintenance. According to the mission schedule and the state of other equipment, determine whether to allow the equipment to exit the mission and whether to repair the equipment.

Red level

The equipment is allowed to exit the mission and enter the maintenance state. The corresponding maintenance work is carried out according to the support resources.

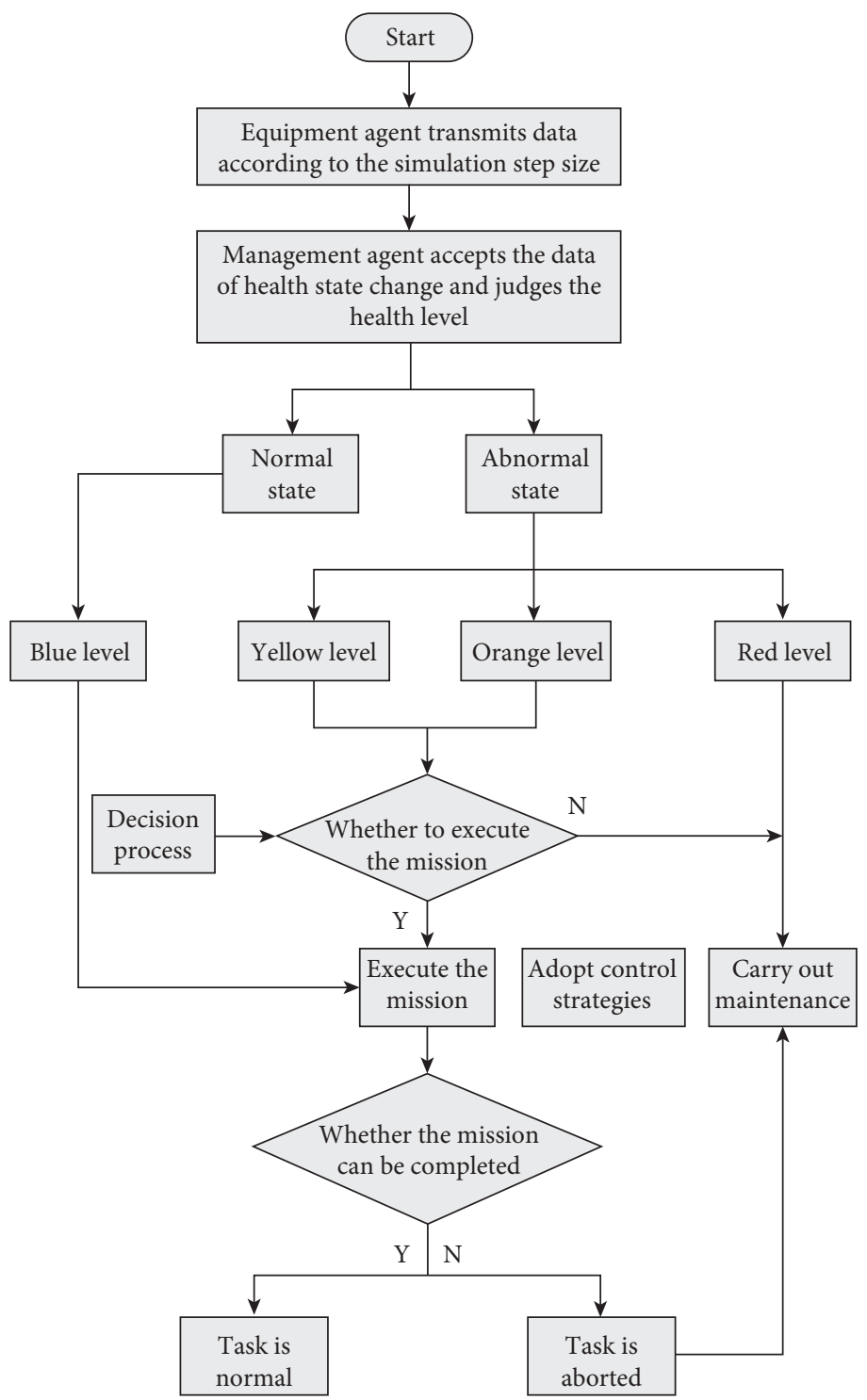

Figure 8: Health control logic. 


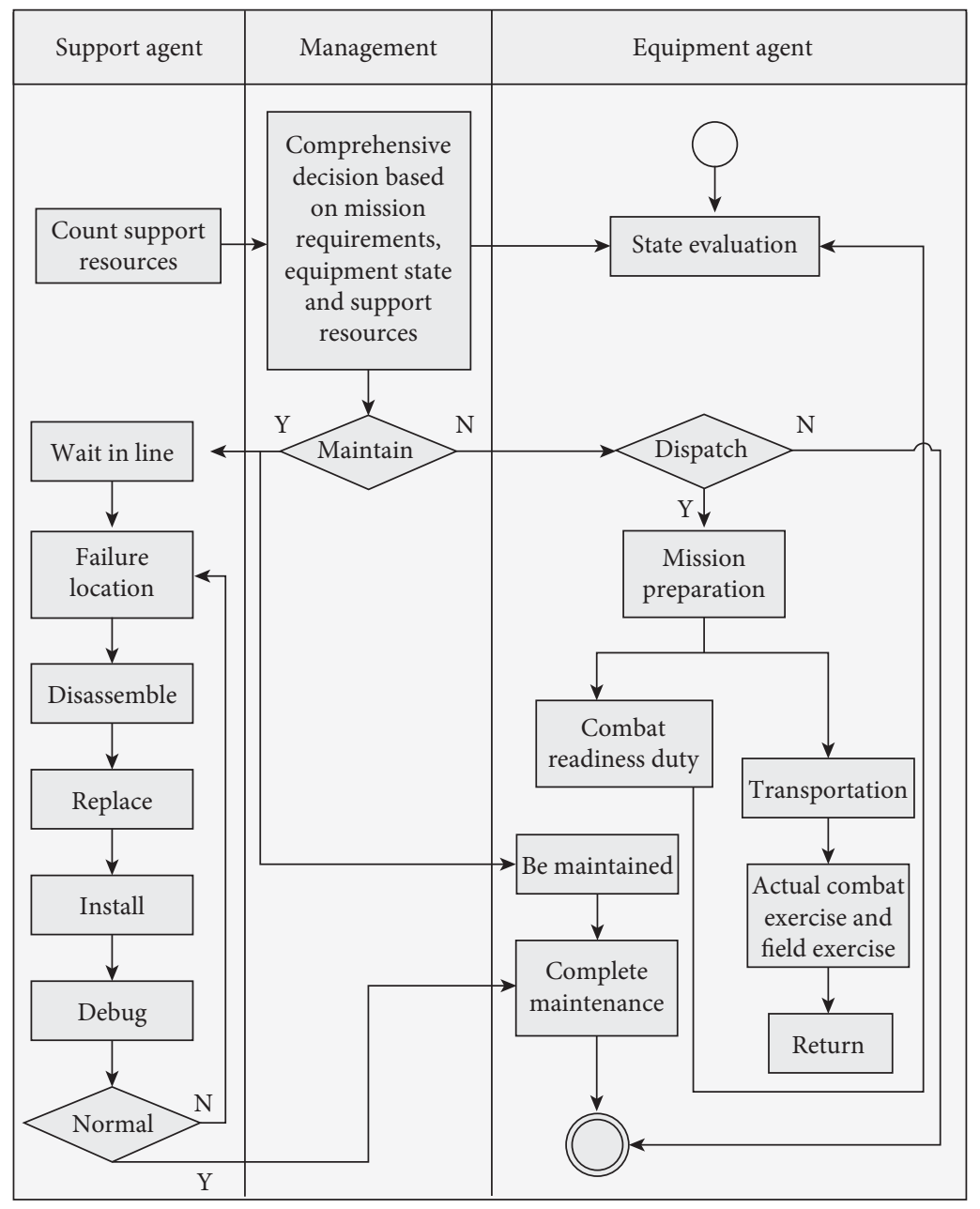

Figure 9: Corrective maintenance model.

failure-based maintenance unit. Secondly, determine the content and sequence of the equipment mission. Thirdly, planning support personnel, maintenance equipment, spare parts, tools, and other support resources. Finally, the equipment support system model is built and the simulation is carried out based on the mission.

5.1. Equipment State Change Type Analysis. The missile equipment consists of various subsystems, including mechanical equipment, electrical system, hydraulic system, and so on. The different subsystems contain many device units. Taking the launch vehicle as an example, its composition is shown in Figure 11. According to the design principle of each device unit and FMEA analysis, it is determined that the generator set $(\mathrm{H} 1)$, power supply combination $(\mathrm{H} 2)$, servo power (H3), etc., are health-based maintenance units. The auxiliary frame (F1), landing gear $(\mathrm{F} 2)$, rotary contact device (F3), power take-off device (F4), etc., are failure-based maintenance units.

5.2. Mission Planning. Determine the mission plan including actual combat exercise, field exercise, and daily duty. Set the mission period as 2 years (720 days). Among them, the equipment performs 8 actual combat exercise missions for a total of 200 days; 6 field exercise missions for a total of 120 days; first-level combat readiness duty for 180 days; second-level combat readiness duty for 120 days; and thirdlevel combat readiness duty for 100 days. On duty, field exercise and actual combat exercise are carried out alternately. All kinds of mission times include transportation, storage, and startup time. A typical mission profile is shown in Figure 12.

5.3. Support Resources Planning. Support resources refer to all resources in the mission profile related to maintenance activities. Resources such as maintenance personnel, maintenance facilities, tools, spare parts, and technical documents may vary according to different maintenance tasks.

Failure-based support resources should be planned based on typical failure modes of different equipment. Table 3 lists some support resources.

On the basis of failure-based support resources, some test device and tools are reduced, and some sensor-related spare parts are added to form health-based support resources. The health-based support resources are planned 


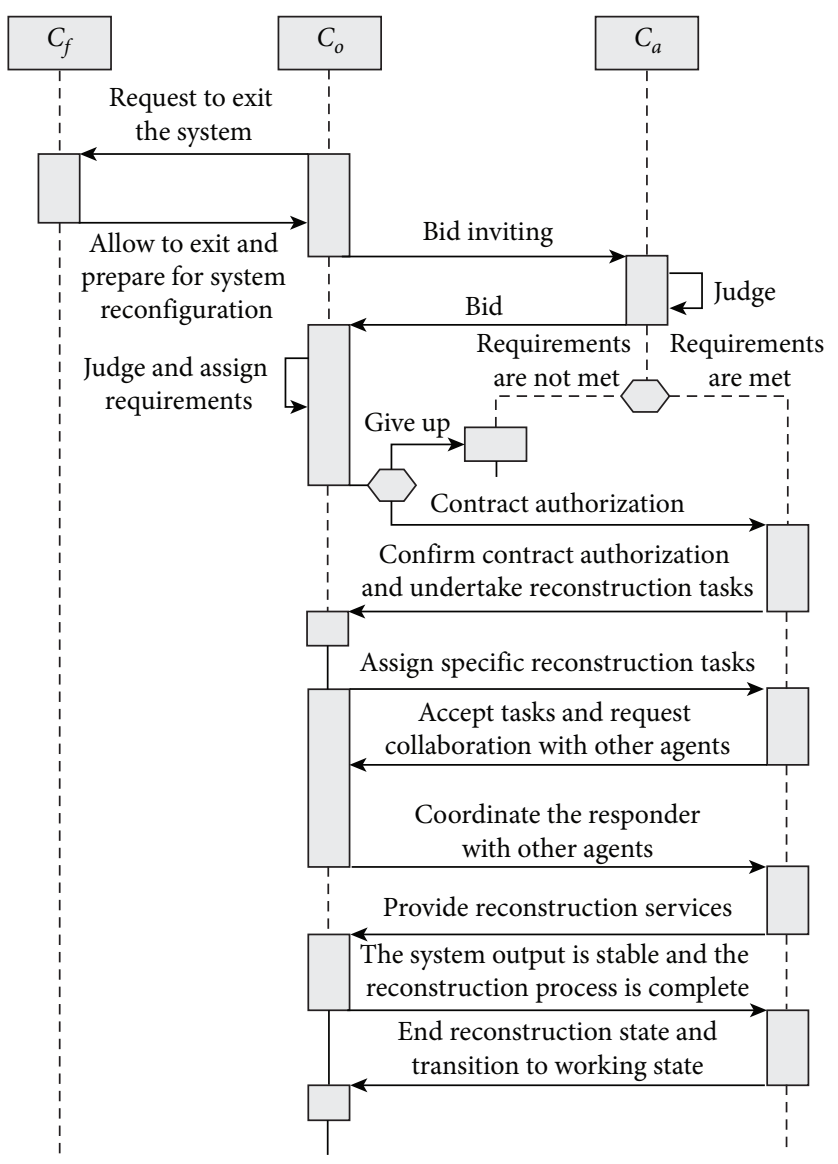

FIgURE 10: System reconstruction model.

according to the health state level. Table 4 lists some support resources.

5.4. Results Analysis. Take equipment mission planning and initial support scheme, including use support, maintenance support, and support resource planning as inputs, to establish the simulation model of the equipment support system. According to the process data recording and analysis of the simulation calculation of the support system, monthly preventive maintenance time, health-based maintenance time, failure-based maintenance time, and management and support delay time of the equipment from June 2019 to May 2021 are shown in Table 5., wherein $\mathrm{Pm}$ is the preventive maintenance time, $\mathrm{Hm}$ is the health-based maintenance time, Fm is the failure-based maintenance time, Dm is the management and support delay time, and $\mathrm{Tm}$ is the total time.

Among them, equipment preventive maintenance includes monthly maintenance, quarterly maintenance, semiannual maintenance, and annual maintenance, so the preventive maintenance time is longer in August 2019, November 2019, February 2020, May 2020, August 2020, November 2020, February 2021, and May 2021. According to these data, equipment availability can be calculated, as shown in Figure 13.
It can be seen that the availability of equipment is high in the early stage. With the execution of the mission such as the actual combat exercise and the field exercise, equipment state gradually degrades and even breaks down, and the availability begins to decline. From June to December 2019, the decline was smaller. The reason is that support resources are sufficient, and degraded or faulty equipment can be repaired quickly. From December 2020 to May 2021, the decline was significant. The reason is that the insufficient supply of support resources leads to some degraded or faulty equipment, which cannot be repaired in time.

After several simulations, the times of maintenance considering both failure and health state are compared with maintenance considering the failure, which is shown in Figure 14. Among them, the maintenance considering both failure and health state can be divided into failure-based maintenance and health-based maintenance. Accordingly, the costs of maintenance considering both failure and health state and maintenance considering only failure are shown in Figure 15.

It can be seen that the times of failure-based maintenance is reduced when both failure and health state are considered. The reason is that some equipment has been warned when the health state is degraded, and the corresponding control strategy has been adopted to avoid the occurrence of failure. Costs of maintenance considering 


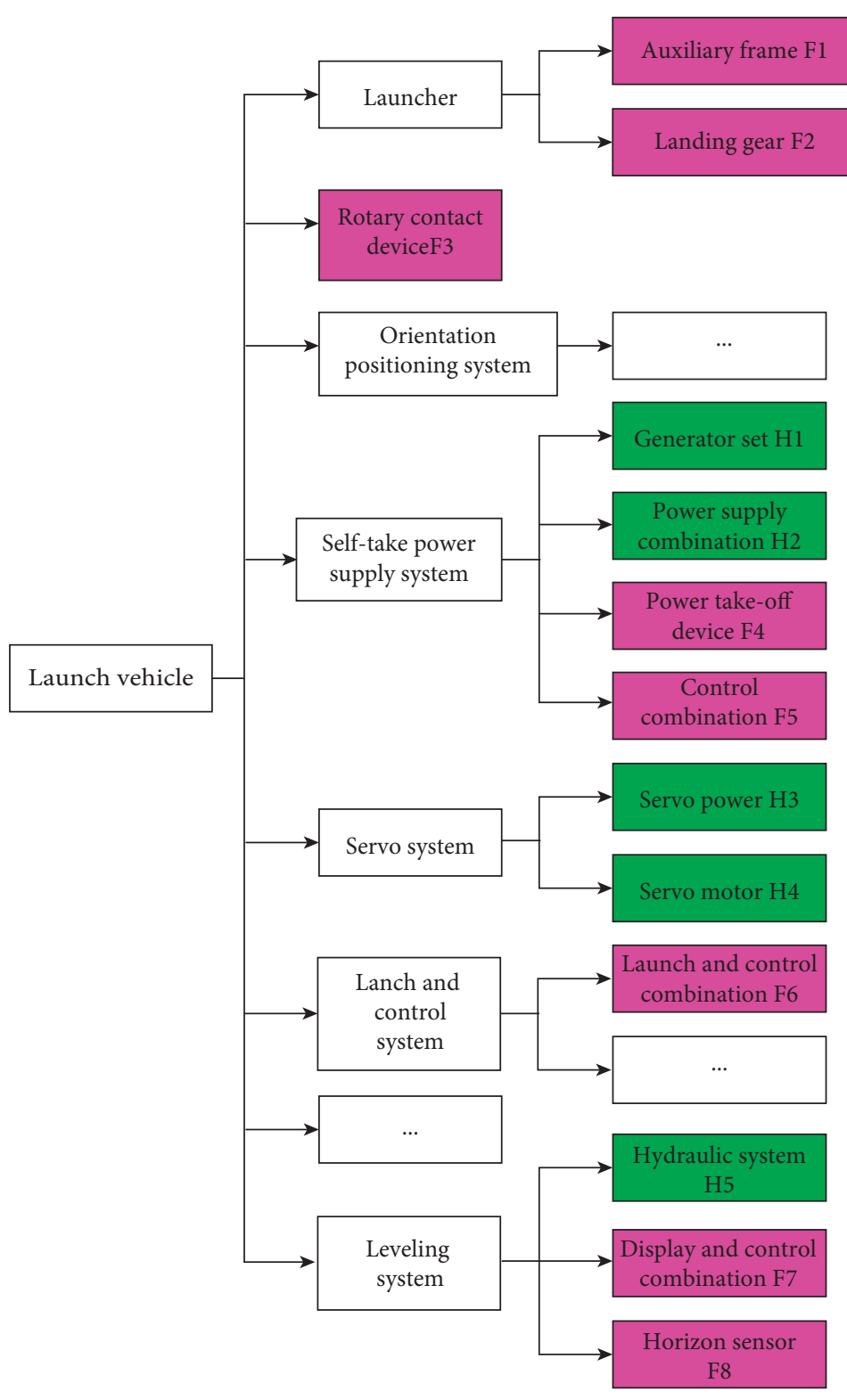

Health-based maintenance units

Failure-based maintenance units

FIGURE 11: Launch vehicle composition.

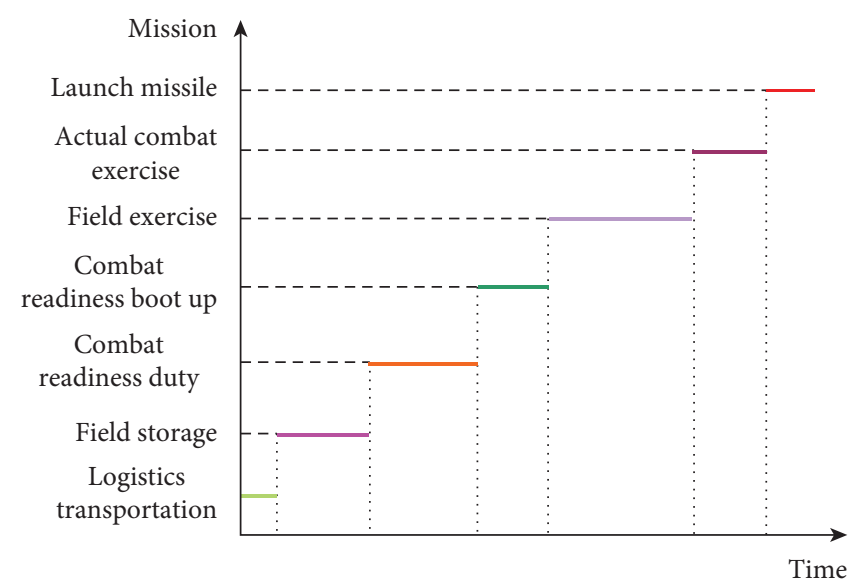

FIgURE 12: Typical mission profile. 
TABLE 3: Failure-based support resources.

\begin{tabular}{lccc}
\hline Equipment & Typical failures & Personnel & Maintenance facilities and tools \\
\hline F1 & Crack & 1 person with mechanical major & Jack, spanner \\
$\ldots$ & $\ldots$ & $\ldots$ & $\ldots$ \\
F5 & No signal & 1 person with electronics major & Voltmeter, screwdriver \\
$\ldots$ & $\ldots$ & $\ldots$ & $\ldots$ \\
Equipment & Typical failures & Spare parts & Technical documents \\
F1 & Crack & Frame & Maintenance card \\
$\ldots$ & $\ldots$ & $\ldots$ & $\ldots$ \\
F5 & No signal & Relay & Operation and maintenance instruction \\
$\ldots$ & $\ldots$ & $\ldots$ & $\ldots$ \\
\hline
\end{tabular}

TABle 4: Health-based support resources.

\begin{tabular}{|c|c|c|c|}
\hline Equipment & Health levels & Personnel & Maintenance facilities and tools \\
\hline \multirow{3}{*}{ H5 } & 4 & No & No \\
\hline & 3 & 1 cleaning staff & Custer cloth \\
\hline & $\cdots$ & 1 person with hydraulic major & $\begin{array}{c}\ldots \\
\text { Disassembly table, flowmeter }\end{array}$ \\
\hline$\ldots$ & & . & \\
\hline \multirow[t]{2}{*}{ Equipment } & Health levels & Spare parts & Technical documents \\
\hline & 4 & No & No \\
\hline \multirow{3}{*}{ H5 } & 3 & No & Preventive maintenance instruction \\
\hline & $\cdots$ & $\ldots$ & $\cdots$ \\
\hline & 1 & Tube & Product specification \\
\hline
\end{tabular}

TABLE 5: Equipment monthly maintenance time.

\begin{tabular}{|c|c|c|c|c|c|}
\hline Date & $\mathrm{Pm}(\mathrm{h})$ & $\mathrm{Hm}(\mathrm{h})$ & $\mathrm{Fm}(\mathrm{h})$ & $\mathrm{Dm}(\mathrm{h})$ & $\operatorname{Tm}(\mathrm{h})$ \\
\hline 2019.06 & 14.21 & 0.16 & 0 & 0.18 & 14.55 \\
\hline 2019.07 & 14.21 & 0.20 & 0 & 0.23 & 14.64 \\
\hline 2019.08 & 14.50 & 0.23 & 0.35 & 0.42 & 15.5 \\
\hline 2019.09 & 14.26 & 0.37 & 0.67 & 3.29 & 18.59 \\
\hline 2019.10 & 14.26 & 0.14 & 0 & 0 & 14.4 \\
\hline 2019.11 & 14.67 & 0.79 & 0.58 & 4.51 & 20.55 \\
\hline 2019.12 & 14.13 & 0.18 & 0 & 0.17 & 14.48 \\
\hline 2020.01 & 14.13 & 0.56 & 0.11 & 4.65 & 19.45 \\
\hline 2020.02 & 14.49 & 1.07 & 0.62 & 10.38 & 26.56 \\
\hline 2020.03 & 14.28 & 0.47 & 0.39 & 7.74 & 22.88 \\
\hline 2020.04 & 14.25 & 0.25 & 0.84 & 4.46 & 19.8 \\
\hline 2020.05 & 15.94 & 0.65 & 0.55 & 5.52 & 22.66 \\
\hline 2020.06 & 14.37 & 1.33 & 0.97 & 16.69 & 33.36 \\
\hline 2020.07 & 14.37 & 0 & 0.68 & 0.83 & 15.88 \\
\hline 2020.08 & 14.86 & 1.64 & 1.32 & 18.91 & 36.73 \\
\hline 2020.09 & 14.42 & 1.02 & 1.52 & 20.85 & 37.81 \\
\hline 2020.10 & 14.42 & 1.79 & 1.04 & 29.73 & 46.98 \\
\hline 2020.11 & 15.25 & 1.36 & 0.43 & 31.63 & 48.67 \\
\hline 2020.12 & 14.43 & 1.92 & 1.06 & 40.92 & 58.33 \\
\hline 2021.01 & 14.43 & 2.83 & 1.19 & 42.32 & 60.77 \\
\hline 2021.02 & 15.29 & 2.92 & 1.87 & 52.57 & 72.65 \\
\hline 2021.03 & 14.41 & 4.55 & 1.92 & 64.68 & 85.56 \\
\hline 2021.04 & 14.41 & 5.78 & 2.04 & 74.43 & 96.66 \\
\hline 2021.05 & 15.67 & 5.61 & 1.26 & 52.51 & 75.05 \\
\hline
\end{tabular}




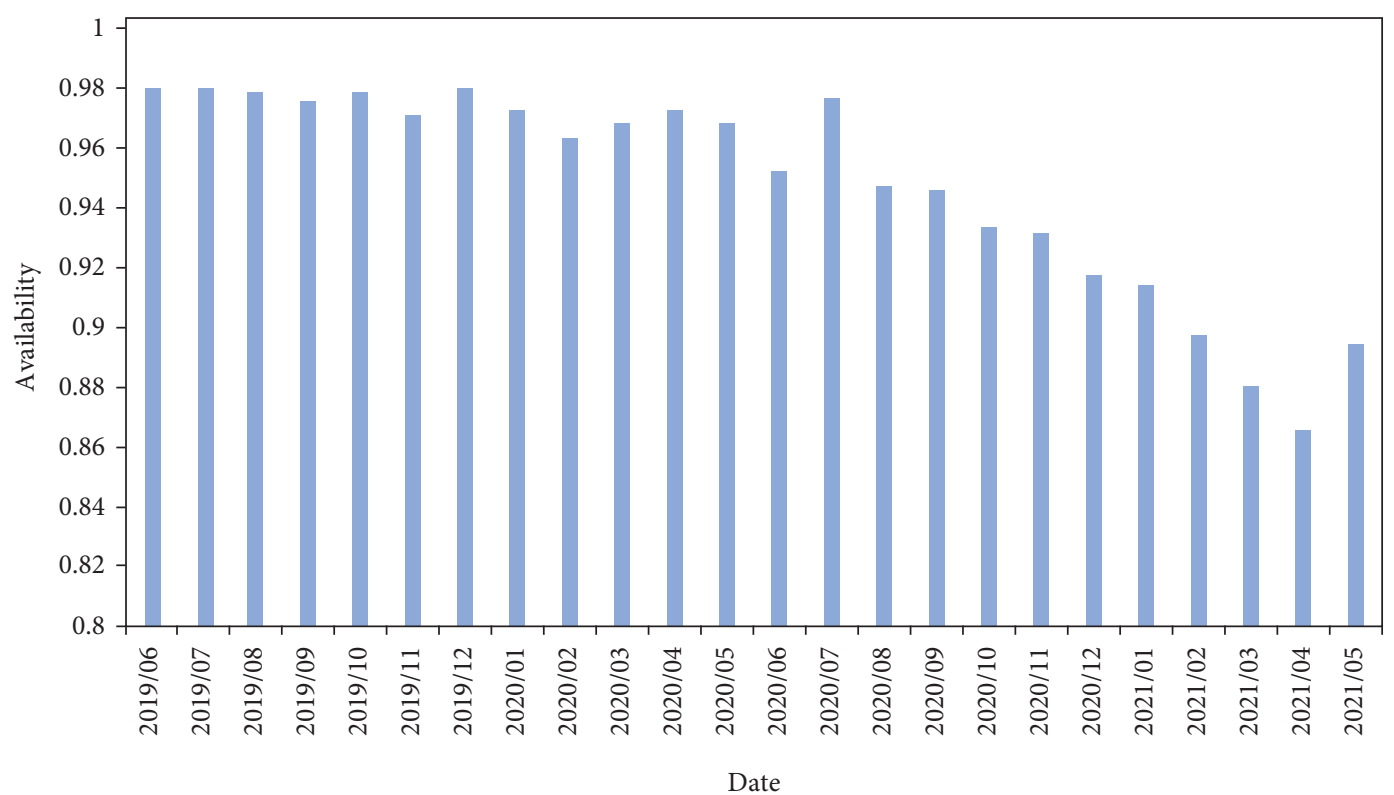

FIgURE 13: Availability distribution.

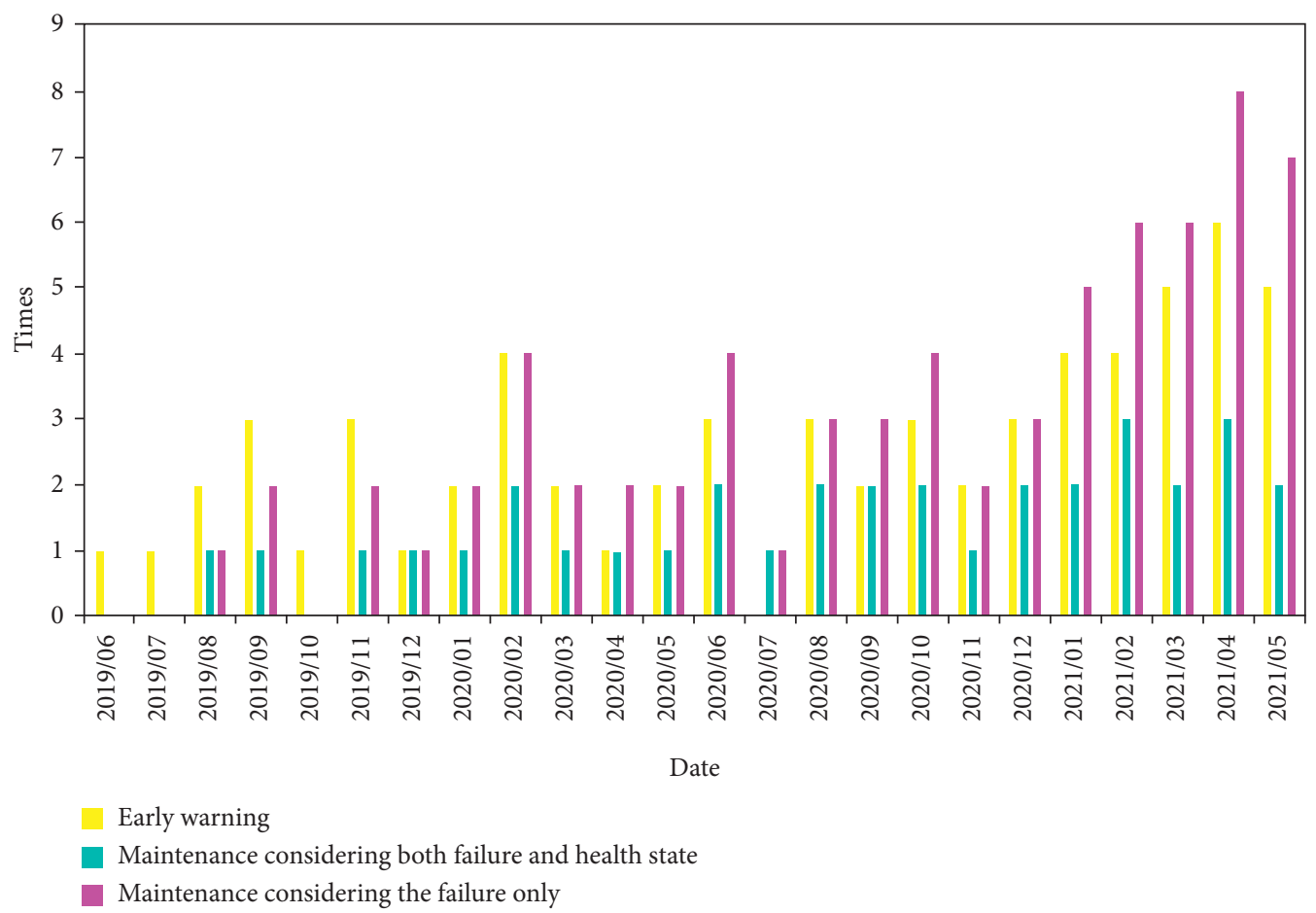

Figure 14: Maintenance times comparison.

both failure and health state are reduced, especially in the later stage. The reason is that the probability of equipment failure can be effectively reduced by reasonable health control strategy. On the one hand, it avoids excessive maintenance; while on the other hand, it reduces medium repair and overhaul. The replacement of spare parts is reduced, and the maintenance hours are shortened.
Maintenance equipment costs, labor costs, and downtime costs are reduced.

Furthermore, the mean time between failures (MTBF) of the equipment can be calculated. When the failure-based maintenance and health-based maintenance are considered comprehensively, the MTBF is $109 \mathrm{~h}$. When only the failurebased maintenance is considered, the MTBF is $51 \mathrm{~h}$. It shows 


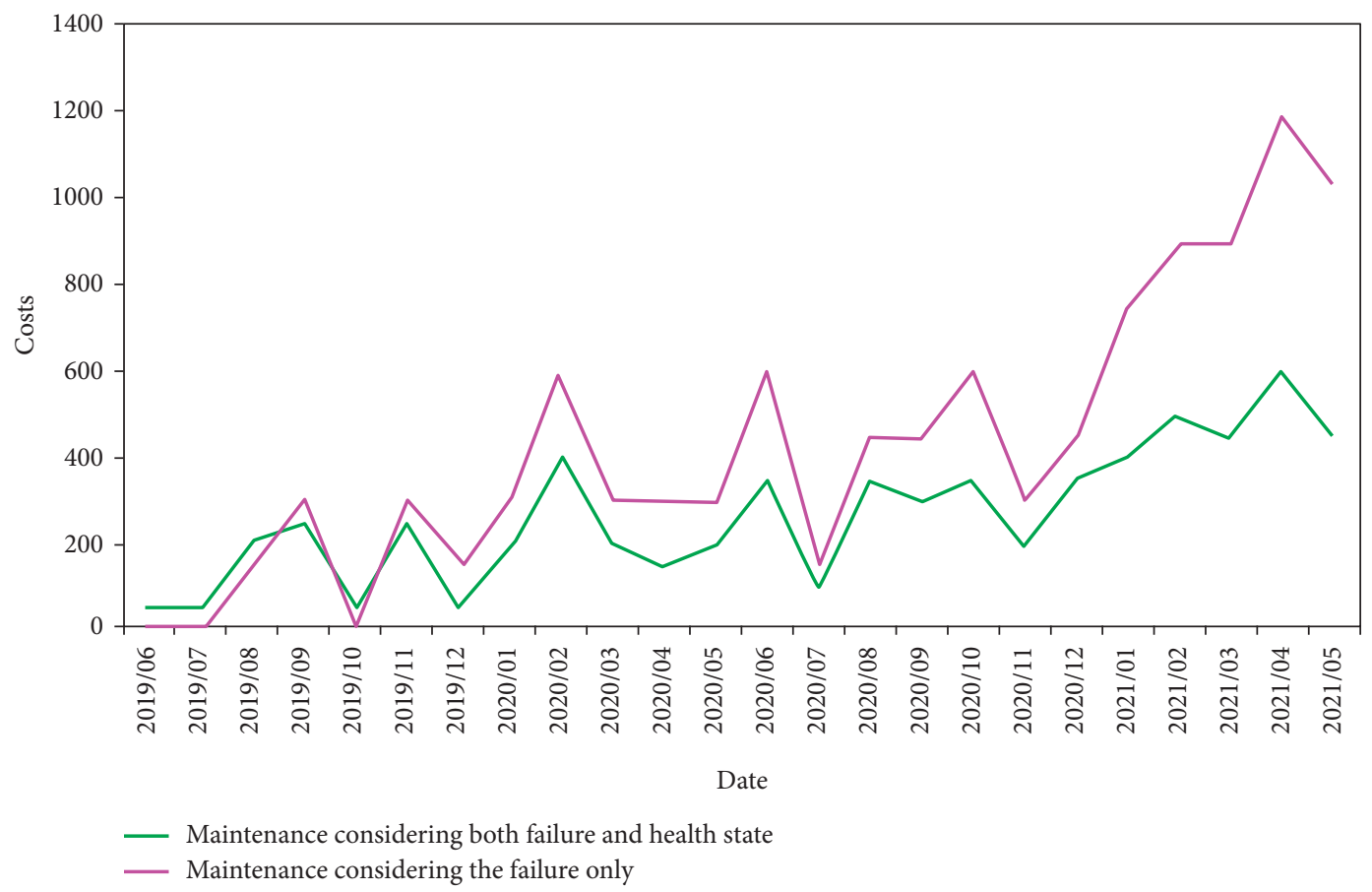

Figure 15: Maintenance costs comparison.

that the support system that considers failure and the health state comprehensively can improve the reliability of the equipment, thereby increasing the availability.

\section{Conclusion}

This paper presents a modeling and simulation method for missile equipment support system which considers failure and health state comprehensively. A mission-oriented simulation model is constructed based on agent technology. This method makes full use of the support data of missile equipment, considers all kinds of equipment attributes, and builds a model close to the actual characteristics of the equipment. According to the different health states, the corresponding control strategies are formulated. Equipment maintenance and support work are carried out in advance to improve the health level. The degradation of equipment health state is prevented in time, reducing the maintenance and support work. The results of an example show that this method can reduce the times of corrective maintenance and prolong the MTBF, thereby improving the availability. The results can play a good guiding role in the formulation of follow-up missile equipment maintenance support decisionmaking and the optimization of support resource allocation, and have great engineering application value. In addition, there is mutual feedback and continuous improvement between the support simulation system and the actual support system of the missile equipment. The parameters and operating mechanism settings of the simulation system should be continuously compatible with the actual equipment, and the actual support system of the equipment should be continuously optimized based on the output results of the simulation system. Based on this cyclic process, the support simulation system can be self-improved and updated with the continuous development and accumulation of equipment maintenance support practices, and solve the problem of missile equipment support decision more effectively [24].

\section{Data Availability}

The data involved in this paper are the use and support data of a certain type of missile equipment in China. The data were collected from industry and users.

\section{Conflicts of Interest}

The authors declare that they have no conflicts of interest.

\section{Acknowledgments}

This work was supported by the State Administration of Science, Technology and Industry for National Defence of China under Grant JCKY2017204A011.

\section{References}

[1] S. Sommerer, M. D. Guevara, M. A. Landis, M. S. Jack, and C. J. Grant, "Systems-of-systems engineering in air and missile defense," John Hopkins APL Technical, vol. 31, no. 1, pp. 5-20, 2012.

[2] Z. Cheng, L. Fan, and Y. Zhang, "A framework for equipment systems-of-systems effectiveness evaluation using parallel experiments approach," Journal of Systems Engineering and Electronics, vol. 26, no. 2, pp. 292-300, 2015.

[3] J. H. Holland, "Studying complex adaptive systems," Journal of Systems Science and Complexity, vol. 19, no. 1, pp. 1-8, 2006. 
[4] Y. Zhang, J. Andrews, S. Reed, and M. Karlberg, "Maintenance processes modelling and optimisation," Reliability Engineering \& System Safety, vol. 168, pp. 150-160, 2017.

[5] C. M. Macal and M. J. North, "Tutorial on agent-based modelling and simulation," Journal of Simulation, vol. 4, no. 3, pp. 151-162, 2010.

[6] B. Liu, M. Xie, and W. Kuo, "Reliability modeling and preventive maintenance of load-sharing systemswith degrading components," IIE Transactions, vol. 48, no. 8, pp. 699-709, 2016.

[7] H. Hu, Z. Li, and A. Al-Ahmari, ““'”Reversed fuzzy Petri nets and their application for fault diagnosis," Computers \& Industrial Engineering, vol. 60, no. 4, pp. 505-510, 2011.

[8] Y. F. Li, E. Zio, and Y. H. Lin, "A multistate physics model of component degradation based on stochastic petri nets and simulation," IEEE Trans Reliab, vol. 61, no. 4, pp. 21-31, 2012.

[9] J. Zhou, "A fuzzy petri-net approach for fault analysis considering factor influences," IEEE Access, vol. 8, Article ID 72229, 2020.

[10] M. Talebberrouane, F. Khan, and Z. Lounis, "Availability analysis of safety critical systems using advanced fault tree and stochastic Petri net formalisms," Journal of Loss Prevention in the Process Industries, vol. 44, pp. 193-203, 2016.

[11] C. Nan, F. Khan, and M. T. Iqbal, "Real-time fault diagnosis using knowledge-based expert system," Process Safety and Environmental Protection, vol. 86, no. 1, pp. 55-71, 2008.

[12] Z. Tian and H. Liao, "Condition based maintenance optimization for multi-component systems using proportional hazards model," Reliability Engineering \& System Safety, vol. 96, no. 5, pp. 581-589, 2011.

[13] Z.-S. Ye, N. Chen, and Y. Shen, "A new class of Wiener process models for degradation analysis," Reliability Engineering \& System Safety, vol. 139, pp. 58-67, 2015.

[14] Z.-S. Ye and M. Xie, "Stochastic modelling and analysis of degradation for highly reliable products," Applied Stochastic Models in Business and Industry, vol. 31, no. 1, pp. 16-32, 2015.

[15] R. Zhao, R. Yan, Z. Chen, K. Mao, P. Wang, and R. X. Gao, "Deep learning and its applications to machine health monitoring," "Mechanical Systems and Signal Processing, vol. 115, pp. 213-237, 2019.

[16] B. Zhang, W. Li, X. L. Li, and S. K. Ng, "'Intelligent fault diagnosis under varying working conditions based on domain adaptive convolutional neural networks," "IEEE Access, vol. 6, Article ID 66367, 2018.

[17] L. A. Rifón and O. S. Llanes, "An approach to multiple fault diagnosis using fuzzy logic," Journal of Intelligent Manufacturing, vol. 30, no. 1, pp. 429-439, 2019.

[18] C. Kiourt, D. Kalles, and G. Pavlidis, "Rating the skill of synthetic agents in competitive multi-agent environments," Knowledge and Information Systems, vol. 58, no. 1, pp. 35-58, 2019.

[19] C. J. Lynch, S. Y. Diallo, and A. Tolk, "Representing the ballistic missile defense system using agent-based modeling," in Proceedings of the Military Modeling \& Simulation Symposium, pp. 1-8, Adelaide, South Australia, December 2013.

[20] M. Barbati, G. Bruno, and A. Genovese, "Applications of agent-based models for optimization problems: a literature review," Expert Systems with Applications, vol. 39, no. 5, pp. 6020-6028, 2012.

[21] B. Heath, R. Hill, and F. Ciarallo, "A survey of agent-based modeling practices," Journal of Artificial Societies and Social Simulation, vol. 12, no. 4, pp. 1-35, 2009.

[22] J. Lee and M. Mitici, “An integrated assessment of safety and efficiency of aircraft maintenance strategies using agent-based modelling and stochastic Petri nets," Reliab Eng Syst Saf, vol. 202, Article ID 107052, 2020.

[23] I. Cil and M. Mala, "A multi-agent architecture for modelling and simulation of small military unit combat in asymmetric warfare," Expert Systems with Applications, vol. 37, no. 2, pp. 1331-1343, 2010.

[24] C. D. Connors, J. O. Miller, and B. J. Lunday, "Using agentbased modeling and a designed experiment to simulate and analyze a new air-to-air missile," The Journal of Defense Modeling and Simulation: Applications, Methodology, Technology, vol. 12, no. 5, pp. 1-10, 2015.

[25] B. U. Nguyen, "Assessment of a ballistic missile defense system," Defense \& Security Analysis, vol. 30, no. 1, pp. 4-16, 2014.

[26] B. Liu, M. Xie, Z. Xu, and W. Kuo, "An imperfect maintenance policy for mission-oriented systems subject to degradation and external shocks," Computers \& Industrial Engineering, vol. 102, pp. 21-32, 2016.

[27] S. H. Sheu, T. H. Liu, Z. G. Zhang, X. F. Zhao, and Y. H. Chien, "A generalized age-dependent minimal repair with random working times," Computers \& Industrial Engineering, vol. 156, Article ID 107248, 2021.

[28] K. T. Huynh, A. Barros, C. Bérenguer, and I. T. Castro, “A periodic inspection and replacement policy for systems subject to competing failure modes due to degradation and traumatic events," Reliability Engineering \& System Safety, vol. 96, no. 4, pp. 497-508, 2011.

[29] Y. Shi, W. Zhu, Y. Xiang, and Q. Feng, "Condition-based maintenance optimization for multi-component systems subject to a system reliability requirement," Reliab Eng Syst Saf, vol. 202, Article ID 107042, 2020.

[30] H. Li, R. Yuan, and J. Fu, "A reliability modeling for multicomponent systems considering random shocks and multistate degradation," IEEE Access, vol. 7, Article ID 168805, 2019.

[31] R. Jiang, "Optimization of alarm threshold and sequential inspection scheme," Reliability Engineering \& System Safety, vol. 95, no. 3, pp. 208-215, 2010.

[32] L. Shen, Y. Wang, Q. Zhai, and Y. Tang, "Degradation modeling using stochastic processes with random initial degradation," IEEE Transactions on Reliability, vol. 68, no. 4, pp. 1320-1329, 2019.

[33] B. Liu, Z. Liang, A. K. Parlikad, M. Xie, and W. Kuo, "Condition-based maintenance for systems with aging and cumulative damage based on proportional hazards model," Reliability Engineering \& System Safety, vol. 168, pp. 200-209, 2017. 